\title{
Decline of the Madagascar radiated tortoise Geochelone radiata due to overexploitation
}

\author{
Susan O'Brien, Ellis R. Emahalala, Vicki Beard, Riana M. Rakotondrainy, Ailsa Reid, Vola Raharisoa \\ and Tim Coulson
}

\begin{abstract}
To avoid the risk of misapplying conservation effort the correct diagnosis of the agent causing a population to decline requires scientific approaches. The radiated tortoise Geochelone radiata, endemic to southern Madagascar, is heavily harvested for food and for the pet trade. Fearing overexploitation, the tortoise was protected under Malagasy law and placed on Appendix I of CITES, yet scientific evidence that the radiated tortoise is declining, and that exploitation is the agent driving any decline, is lacking. Interviews with tortoise harvesters, a comparison of the size of the tortoise's range through time, and estimates of tortoise abundance at 14 sites under different levels of harvest intensity were used to seek evidence of overexploitation. In the first study to attempt to quantify the size of the illegal harvest of radiated tortoises, we estimated that up to 45,000 adult radiated tortoises are harvested each year. The species is
\end{abstract}

declining, with its range having contracted by onefifth over the last 25 years. Three pieces of evidence strongly suggest that overexploitation is driving this decline. Firstly, commercial harvesters reported travelling increasingly far, up to $200 \mathrm{~km}$, to find sufficient densities of tortoises. Secondly, tortoises were either absent or at very low abundance at sites subject to commercial harvesting, but in remote, unharvested regions, tortoises persisted at densities of up to $2,500 \mathrm{~km}^{-2}$. Thirdly, tortoise abundance increased significantly with distance from urban centres of high demand for tortoise meat. If current rates of harvesting continue, the radiated tortoise will go extinct in the wild.

Keywords Geochelone radiata, geographic range, harvesting, Madagascar, population size, radiated tortoise.

on the cause of the decline. To successfully diagnose this it must first be confirmed that a population is declining and then the agent of decline needs to be identified. The comparative approach uses correlation between population changes and an agent, both over time in the same area and among areas within the same time period, to identify the agent of decline (Green, 2002).

The radiated tortoise Geochelone radiata is a large terrestrial reptile, endemic to the spiny forests of southern Madagascar. The tortoise is extensively harvested for food and for the pet trade. Tortoises are taken for the food, pet and souvenir markets at the local, national and international level, and both for subsistence and commercial use. Demand for tortoises has high spatial variability. For cultural reasons tortoises are rarely consumed by indigenous people living within the tortoise's current range, but demand for tortoise meat is high in the towns of Toliara and Tolagnaro, on the edge of the current range. Commercial harvesters from these cities transport tortoises by oxcart and fishing boat. Lewis (1995) and Nussbaum and Raxworthy (2000) provide further details on the harvest. Fearing overexploitation, legislation to protect the tortoise under Malagasy law was introduced in 1961 and the species listed on Appendix I of CITES in 1975. This tortoise is categorized as Vulnerable 
on the IUCN Red List (Lewis, 1995; IUCN, 2002) based on both a population reduction and a limited extent of occurrence. Despite this, scientific evidence identifying overexploitation as the cause of any population decline in the radiated tortoise is lacking.

Preliminary surveys of the geographic range of the radiated tortoise implied that the range had decreased, yet made no comparisons with previous estimates of range size (Decary, 1950; Juvik, 1975). In 1995 Lewis (1995) made presence/absence observations of the radiated tortoise throughout its range but detected an increase in range size, compared with 1975 estimates (Juvik, 1975), apparently due to an underestimation of range size in 1975.

This study presents the first published estimates of the number of radiated tortoises harvested annually. The range of the species in 2000 is compared with previous estimates of range size, seeking evidence that the tortoise population is declining. The hypothesis that exploitation is the main agent causing a decline is tested using the comparative approach. Change in tortoise abundance through time and space, relative to harvest intensity, is examined.

\section{Methods}

\section{Size of the annual harvest}

An estimate of the annual harvest of radiated tortoises was acquired by interviewing harvesters. Six harvesters from the city of Toliara were individually interviewed by a local Malagasy non-governmental organisation (L'Association de la Sauveguarde de l'Environnement). These harvesters are fishermen who transport tortoises by fishing boat. They represent an unknown fraction of all commercial harvesters. They were questioned about (i) the number of tortoises they collect each trip, (ii) the number of trips they make each month, (iii) the number of tortoise harvesters there are in Toliara, and (iv) the number of years since tortoises were last found within walking distance of Toliara. The mean annual harvest collected by Toliara fishermen was estimated by the product of the mean number of tortoises per fishing boat, the mean number of trips made each year and the mean number of harvesters in Toliara. A range for the estimate of annual harvest was determined from the product of all the minimum values of the number of tortoises taken, the number of trips per year and the number of harvesters, and the product of all the maximum values. The number of months in a year during which harvesters collected tortoises was assumed to be a minimum of six months, an average of nine months and a maximum of 12 months, equally distributed between the wet and dry seasons.

\section{Decrease in geographic range size}

Evidence of a decline in range size was sought by comparing current and historical range area. The approximate geographic range of the radiated tortoise in 1865 was inferred from subfossil specimens and 19th century shipping records of tortoise exports (Vinson, 1865; Bour, 1994; Nussbaum \& Raxworthy, 2000), and the tortoise's range was also described in 1975 and 1995 (Juvik, 1975; Lewis, 1995). The range in 2000 was estimated from tortoise abundance at 14 sites in southern Madagascar (see below) and from anecdotal information obtained during interviews with Waters and Forests Ministry workers of the Madagascar government, nongovernmental organisations, local villagers and harvesters. Change in range size from 1975 to 2000 was investigated by comparing range area estimated from maps.

\section{Decrease in tortoise abundance in harvested areas}

Changes in tortoise abundance with distance from urban centres and with harvest intensity were investigated. Fourteen sites throughout southern Madagascar were visited during October-December 2000 (Fig. 1). The sites were selected using stratified random sampling, by dividing the tortoise's current range into six equal-sized regions and selecting three sites within each region. The three sites were (i) within $5 \mathrm{~km}$ of the coast, (ii) within $5 \mathrm{~km}$ of a major road and (iii) at least $40 \mathrm{~km}$ from either the coast or a major road. Within these constraints, sites were selected randomly. It was impossible to visit four sites for logistical reasons. At each of the remaining 14 sites a $3 \mathrm{~km}$ transect was walked through the least degraded habitat in the area, from 06.30 to 09.30 and 16.00 to 19.00 , avoiding the middle of the day when tortoises become inactive. The perpendicular distance between each tortoise and the transect line was measured. Tortoises were detected up to $28.4 \mathrm{~m}$ from the transect line. The same observers were used throughout the survey. The number of tortoises observed on the $3 \mathrm{~km}$ of transect was used as an index of relative abundance of tortoises. At two sites a sufficient number of tortoises were encountered $(n>60)$ to permit estimation of density using distance sampling (Buckland et al., 1993).

Harvest activity at each of the 14 sites was established by direct observations of harvesting such as oxcarts containing live tortoises (Plate 1) or carapaces of tortoises killed for human consumption (Plate 2), and by interviewing 3-5 local villagers about recent harvesting activity in the area. Sites were described as (i) unharvested if there was no evidence of harvesting and villagers reported that harvesters never visited that area, (ii) subsistence harvested if people from nearby large villages or small towns collected tortoises for their own consumption and 


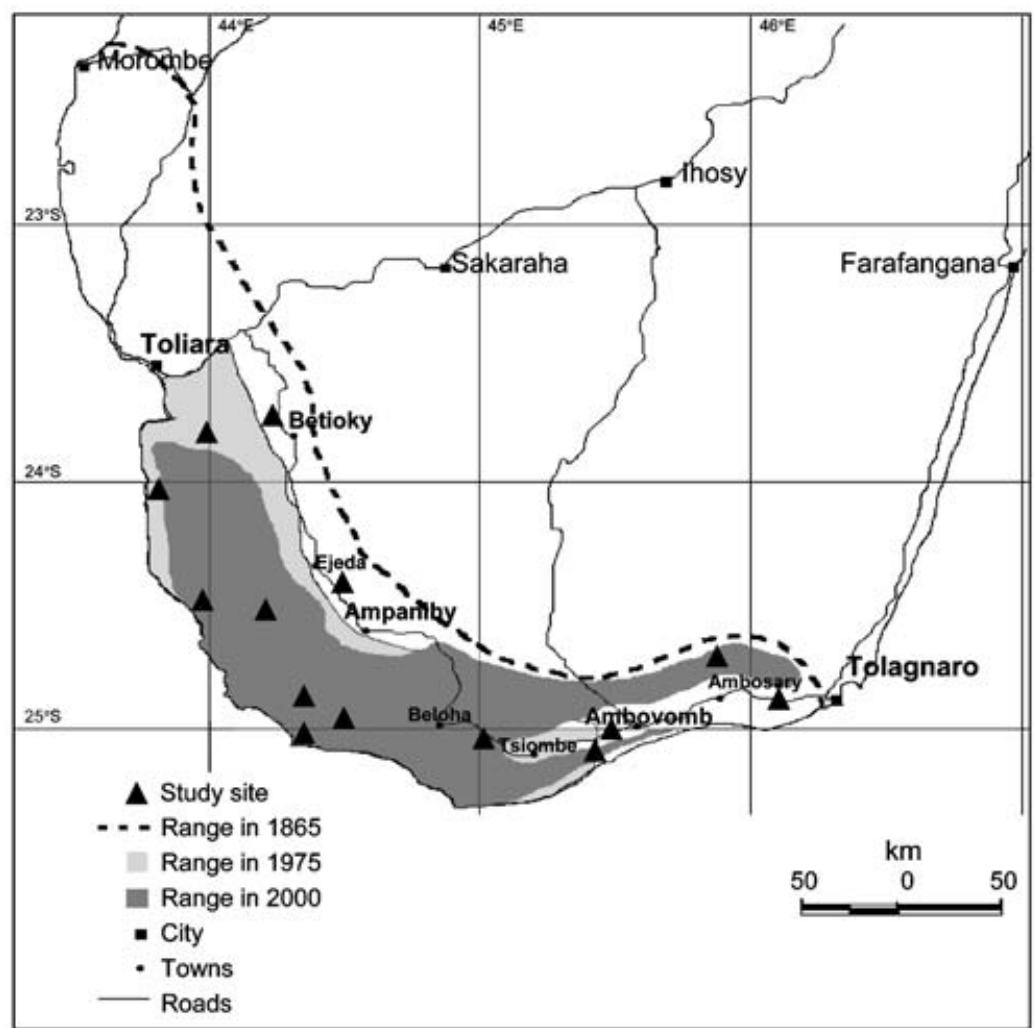

Fig. 1 Map of southern Madagascar, showing the estimated geographic range of the radiated tortoise in the years 1865, 1975 and 2000. The 14 study sites at which tortoise abundance was estimated during OctoberDecember 2000 are marked.

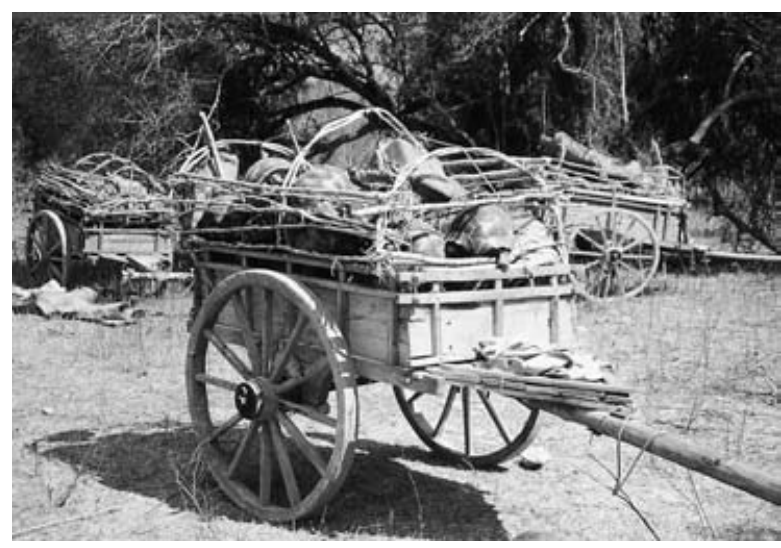

Plate 1 Oxcarts full of live adult radiated tortoises being taken to market in southern Madagascar (S. O’Brien).

(iii) commercially harvested if outsiders collected many tortoises and transported them to large towns or cities for sale.

The relationship between distance from a large urban centre (the cities of Toliara and Tolagnaro) and tortoise abundance, at each of the 14 sites, was investigated using a non-parametric Ordering test (Quenouille, 1952; Sokal \& Rohlf, 1995). Tortoise abundance in the presence of subsistence harvesting, commercial harvesting and in the absence of harvesting was compared using a

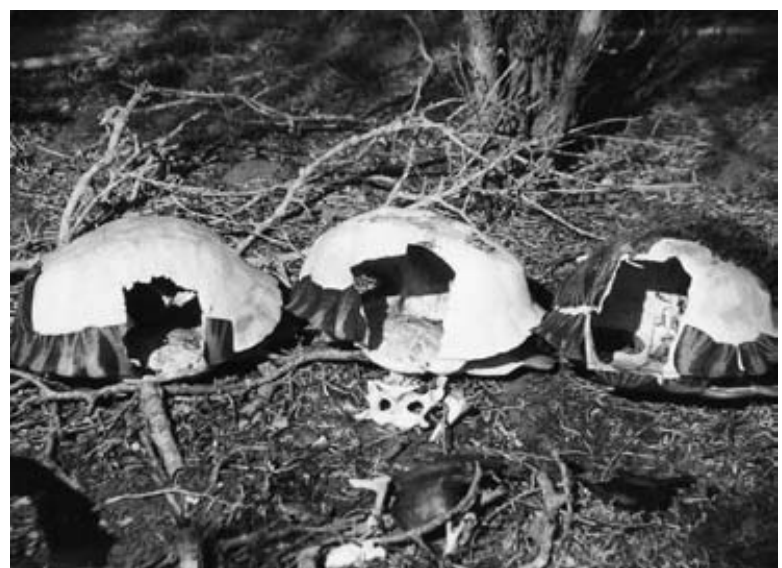

Plate 2 Carapaces of radiated tortoises killed in situ for meat, bearing the distinctive hole in the shell where the tortoise was killed (S. O’Brien).

Kruskal-Wallis non-parametric ANOVA test. Minitab 13.31 was used for all statistical testing.

\section{Results}

\section{Size of the annual harvest of tortoises}

The Toliara harvesters collect thousands of adult radiated tortoises annually and travel increasingly far to find 
sufficient densities of tortoises. There was a high consistency among the responses of the harvesters. They reported making 1-2 trips per month in the dry season and 1-3 trips per month in the wet season, collecting an average of 59 adult tortoises on each trip (Table 1). An estimated 270-2,325 adult tortoises are collected by one group of harvesters each year, assuming harvesters spend a minimum of 6 months and a maximum of 12 months of the year harvesting. One group of harvesters comprises 3-4 people with one fishing boat. Harvesters estimated there to be an average of 13 harvest groups (range 9-20) in Toliara. The six interviewed harvesters stated they never worked together, implying we sampled from almost half of the harvest groups operating from Toliara. Using the minimum and maximum number of tortoises harvested by one group (Table 1) we therefore estimate that all of the harvesters in Toliara who transport tortoises by fishing boat collect 2,430-46,500 (mean $14,130)$ adult radiated tortoises annually. Harvesters reported travelling increasingly far to find sufficient densities of tortoises. They estimated it was 10-20 years since tortoises could be found within easy walking distance of Toliara. Some harvesters sailed further down the coast to find tortoises, whereas others searched further inland, nearer to Toliara, walking up to $20 \mathrm{~km}$.

\section{Decrease in geographic range}

The geographic range of the radiated tortoise has undergone a large decrease over the last 150 years. Historical records strongly suggest that the original range of the tortoise extended further north than Toliara, probably as far as Morombe (Fig. 1). The area of the geographic range in 2000 was $21,875 \mathrm{~km}^{2}$, which represents a decrease of $20.9 \%$ from the $27,650 \mathrm{~km}^{2}$ found by Juvik (1975).

Table 1 Minimum, mean and maximum number of harvesting trips made each month in the dry and wet seasons, number of months of harvesting in each season, number of adult tortoises collected on each trip, and total number of tortoises collected each year by harvesters from Toliara (see text for details of the calculation).

\begin{tabular}{lccc}
\hline & Minimum & Mean & Maximum \\
\hline No. trips in dry season & 1 & 1.4 & 2 \\
$\quad$ No. months of harvesting & 3 & 4.5 & 6 \\
$\quad$ in dry season & 1 & 2.7 & 3 \\
No. trips in wet season & 3 & 4.5 & 6 \\
$\quad$ No. months of harvesting & & & \\
$\quad$ in wet season & 45 & 59.0 & 76 \\
No. adult tortoises collected & & & \\
$\quad$ each trip & 270 & 1,087 & 2,325 \\
$\quad$ Total number of tortoises & & & \\
$\quad$ collected each year & & & \\
\hline
\end{tabular}

\section{Decrease in tortoise abundance in harvested areas}

Tortoise abundance exhibited considerable spatial heterogeneity, with the index of relative tortoise abundance varying from 0 to 89 tortoises (mean $=15.2 \pm$ SE 7.5). Most sites supported few tortoises and at only two sites, in the far south-west of Madagascar, was a high abundance of tortoises recorded. Density at these sites was estimated to be 1,584 tortoises $\mathrm{km}^{-2}(1,201-$ 2,087 tortoises $\mathrm{km}^{-2}, 95 \%$ confidence interval) and 2,439 tortoises $\mathrm{km}^{-2}\left(1,771-3,358\right.$ tortoise $\mathrm{km}^{-2}, 95 \%$ confidence interval).

Geographical location of sites influenced abundance. The highest abundances occurred at sites furthest from the cities of Toliara and Tolagnaro, in which demand for tortoise meat is high (Fig. 2). Tortoise abundance increased significantly with distance from a city (ordering test $r=0.614, \mathrm{P}=0.019$ ). At sites closest to the cities very few or no tortoises were found. Only three of the 14 sites were unharvested and commercial harvesting is currently occurring in areas $>200 \mathrm{~km}$ from centres of high demand for tortoise meat (S. O'Brien, E. Emahalala and A. Reid, pers. obs., Fig. 2). Tortoise abundance at commercially harvested sites was consistently low (mean $=1.8 \pm \mathrm{SE} 1.1)$. Abundance at subsistence and unharvested sites was greater on average but was highly variable (subsistence harvested mean = $21.2 \pm$ SE 17.1; unharvested mean $=32.0 \pm$ SE 19.1) and abundance did not significantly alter with increasing harvest intensity (Kruskal-Wallis ANOVA $\mathrm{H}_{2}=3.87$, $\mathrm{P}=0.144)$.

\section{Discussion}

The annual harvest of radiated tortoises is extensive, the tortoise population has declined and there is good evidence that overexploitation has caused this decline. Up to 46,500 adult radiated tortoises are collected from the wild each year by harvesters from the city of Toliara, and this represents an unquantified fraction of the total annual harvest. We found four pieces of evidence of overexploitation. Firstly, during the last 25 years the geographic range of the radiated tortoise is estimated to have contracted by c. $20 \%$. Secondly, commercial harvesters are obliged to travel increasingly far to find sufficient densities of tortoises and are presently harvesting in areas more than $200 \mathrm{~km}$ from the urban centres of Toliara and Tolagnaro, where most commercially harvested tortoises are sold. Thirdly, tortoises were either absent or at very low abundance at sites subject to commercial harvesting; abundance was higher on average, but highly variable, at subsistence harvested and unharvested sites and, in the most remote regions, tortoises still persist at densities of up to $c .2,500 \mathrm{~km}^{-2}$. 
Fig. 2 Relative index of tortoise abundance (number seen whilst walking along a $3 \mathrm{~km}$ transect) at 14 sites in southern Madagascar centre (Toliara or Tolagnaro). against distance from the nearest urban

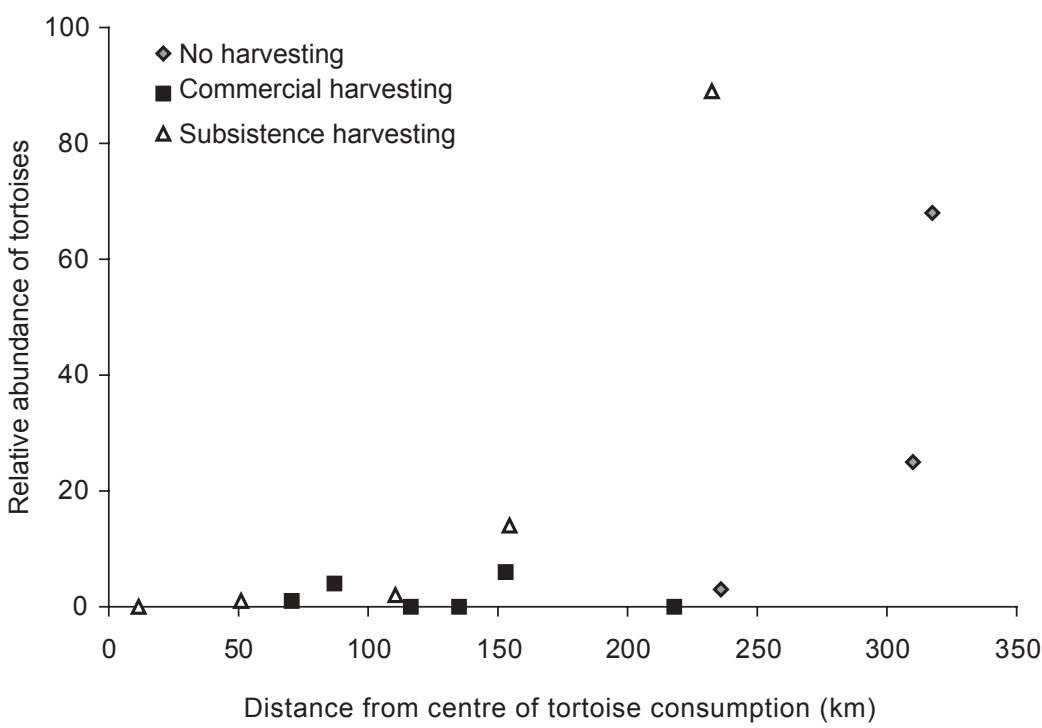

Fourthly, tortoise abundance was spatially heterogeneous and increased significantly with distance from urban centres.

This study demonstrated that the radiated tortoise population has declined during the twentieth century. The geographic range has contracted by $>20 \%$ over 25 years, and potentially $>50 \%$ since 1865 . The IUCN categorizes species as Vulnerable, Endangered or Critically Endangered, if they have undergone a 20, 50 or $80 \%$ decrease in range size, respectively, during the last three generations or 10 years, whichever is longer (IUCN, 2002). Generation time in the radiated tortoise is unknown but, because of its great longevity and delayed maturity, must be long (Robb \& Turbott, 1977; O’Brien, 2002). The radiated tortoise is certainly Vulnerable (its current Red List categorization), as it has undergone a $>20 \%$ decrease within $>10$ years, and may be Endangered if the 1865 range estimated in this study is correct and generation time is $>45$ years.

Three major anthropogenic processes cause most species' declines: habitat loss, introduced species and overexploitation (IUCN, 2002). All three processes are occurring within the range of the radiated tortoise but there is good evidence that overexploitation is the dominant process currently limiting the population. Radiated tortoises were found by this study, and by Lewis (1995), to persist at high densities in regions of heavily degraded habitat and were at lower abundance in unharvested areas of relatively pristine habitat, including protected areas. Tortoises seemingly benefit from the introduced prickly pear cactus (Opuntia spp.) using it for both shelter and food (S. O'Brien, pers. obs.). In heavily harvested areas tortoises were either extirpated or at very low abundance, and were at high abundance in unharvested areas, strongly suggesting that overexploitation is currently driving the observed decline. However, habitat loss and introduced species are probably also detrimental to radiated tortoises and such impacts and their relative importance requires investigation. Caughley \& Gunn (1996) and Green (2002) recommend viewing a correlation between an agent of decline and population changes as a hypothesis to be tested using supplementary experimental studies. To truly diagnose overexploitation as the agent driving the observed decline in radiated tortoise populations, more detailed empirical and modelling studies of demographic rates under different levels of harvest intensity are required (O'Brien, 2002).

Bennett \& Robinson (2000) identified six factors that influence the sustainability of exploitation: physical, cultural, biological, social, economic and institutional. To date, physical and cultural factors have prevented extinction of the radiated tortoise through overexploitation. Remote areas, far from urban centres, presently remain unharvested due to their inaccessibility, and cultural taboos prohibit consumption of the tortoise throughout much of its range. The high longevity and slow rate of population growth of tortoise populations render them susceptible to overexploitation (Wilbur \& Morin, 1988; Congdon et al., 1993; O’Brien, 2002). However the high density at which radiated tortoises live will increase persistence time as it will take harvesters longer to deplete a high density population. Social factors decrease the sustainability of the radiated tortoise population. The human population in Madagascar is rapidly increasing and demand for tortoise meat is high. Increased migration is eroding traditional beliefs and the Mahafaly and Antandroy people, for whom the tortoise is traditionally taboo, are increasingly starting to consume tortoises (WWF, 1999). Poverty in southern Madagascar encourages harvesters to continue collecting 
tortoises. It will remain profitable for harvesters to travel long distances to collect tortoises so long as demand is high and poverty is rife. Finally, institutional factors are not preventing overexploitation. Although the radiated tortoise is protected under both Malagasy and international law, thousands of tortoises are harvested each year. Current or previous collecting has occurred in all protected areas within the tortoise's range (Razafindrakoto, 1985; Nicholl \& Langrand, 1989; Lewis, 1995; Leuteritz, 2002). The large annual harvest of radiated tortoises is unsustainable and, if current rates of exploitation continue, the radiated tortoise will ultimately go extinct in the wild.

Lewis (1995), Nussbaum \& Raxworthy (2000) and O'Brien (2002) have recommended management actions to conserve the radiated tortoise. Rates of exploitation need to be reduced by decreasing demand (using education and awareness programmes), by provision of alternative income (possibly within community-based conservation schemes), and by improved enforcement of existing law. The short-term goal should be to reduce exploitation rates as quickly as possible. The high density of tortoises in some areas provides some time to reduce exploitation rates to sustainable levels. Because populations are often slow to recover or never recover from small population sizes (Hutchings, 2000) it has to be a better strategy to try and preserve a relatively healthy radiated tortoise population now rather than to conserve small fragmented populations on the verge of extinction in the future.

\section{Acknowledgements}

We are grateful to the Ministère des Eaux et Forêts Madagascar for granting permission for this research, to the Université d'Antananarivo, in particular Dr. Daniel Rakotondravony, for facilitating our research in Madagascar, and L'Association de la Sauveguarde de l'Environnement for interviewing harvesters. WWF, in particular Mark Fenn, provided much logistical support. We also wish to thank Georgina Mace, Matthew Hatchwell, Herilala Randriamahazo and Jörn Scharlemann for providing comments on this manuscript and Richard Lewis, Joanna Durbin, Jean Tinike, Naivoson and Pascal Andriamanambina for useful discussions and assistance in the field. The Natural Environment Research Council and Dr Edward Louis of Henry Doorly Zoo, Omaha, USA, contributed funds to this research.

\section{References}

Bennett, E.L. \& Robinson, J.G. (2000) Hunting for sustainability: the start of a synthesis. In Hunting for Sustainability in Tropical Forests (eds J.G. Robinson \& E.L. Bennett), pp. 499-519.

Columbia University Press, New York, USA.
Bour, R. (1994) Recherches sur des animaux doublement disparus: les tortues géantes subfossiles de Madagascar. Mémoire EPHE.

Buckland, S.T., Anderson, D.R., Burnham, K.P. \& Laake, J.L. (1993) Distance Sampling: Estimating Abundance of Biological Populations. Chapman and Hall, London, UK.

Caughley, G. \& Gunn, A. (1996) Conservation Biology in Theory and Practice. Blackwell Science, Massachusetts, USA.

Congdon, J.D., Dunham, A.E. \& Sels, R.C.V. (1994)

Demographics of common snapping turtles (Chelydra -

Serpentina) - implications for conservation and

management of long-lived organisms. American Zoologist, 34, 397-408.

Decary, R. (1950) La Faune Malgache. Publisher, Paris, France.

Green, R.E. (2002) Diagnosing causes of population declines and selecting remedial actions. In Conserving Bird Biodiversity: General Principles and their Application (eds K. Norris \& D.J. Pain) pp. 139-156. Cambridge University Press, Cambridge, UK.

IUCN (2002) 2002 IUCN Red List of Threatened Species. IUCN, Gland, Switzerland [http:/ / www.redlist.org, accessed 25 April 2003].

Hutchings, J. (2000) Collapse and recovery of marine fishes. Nature, 406, 882-885.

Juvik, J.O. (1975) The radiated tortoise of Madagascar. Oryx, 13, 145-148.

Lewis, R. (1995) Status of the Radiated Tortoise (Geochelone radiata). Unpublished Report, WWF, Madagascar.

Leuteritz, T.E. (2002) Distribution, status, and reproductive biology of the radiated tortoise, Geochelone radiata (Shaw, 1802) in Southwest Madagascar. PhD thesis, George Mason University, Fairfax, Virginia, USA.

Nicholl, M.E. \& Langrand, O. (1989) Madagascar: Revue de la Conservation et des Aires Protegees. WWF, Gland, Switzerland.

Nussbaum, R.A. \& Raxworthy, C.J. (2000) Commentary on conservation of "Sokatra", the radiated tortoise (Geochelone radiata) of Madagascar. Amphibian and Reptile Conservation, 2, 6-14.

O'Brien, S. (2002) Population dynamics and exploitation of the radiated tortoise Geochelone radiata in Madagascar. PhD thesis, University of Cambridge, Cambridge, UK.

Quenouille, M. (1952) Associated Measurements. Academic Press, New York, USA.

Razafindrakoto, L. (1985) Contribution a l'Etude Bio-EcoEthologique de Geochelone radiata (Shaw 1802) (Famille des Testudinidae) dans la Reserve Spéciale de Beza-Mahafaly. PhD thesis, Université de Madagascar, Antananarivo, Madagascar.

Robb, J. \& Tubott, E. (1977) Tu'i Malila, "Cook's Tortoise". Records of the Aukland Institute and Museum, 8, 229-233.

Sokal, R.R. \& Rohlf, F.J. (1995) Biometry. W.H. Freeman, New York, USA.

Vinson, A. (1865) Voyage à Madagascar. A La Librairie Encyclopedique de Roret, Paris, France.

Wilbur, H.M. \& Morin, P.J. (1988) Life History Evolution in Turtles. In Biology of the Reptilia (eds C. Gans \& R.B. Huey) pp. 387-439. Alan R. Liss, New York, USA.

WWF, M.P.O. (1999) Les tendances actuelles de la migration des peoples et son impact dans la region ecologique des forets d'épineux. Antananarivo, Madagascar. 